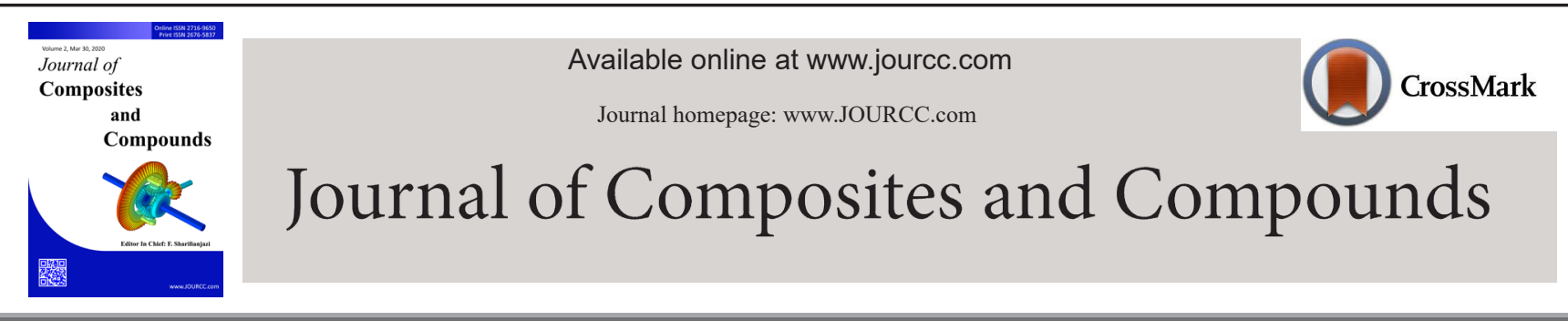

\title{
A review on the Comsol Multiphysics studies of heat transfer in advanced ceramics
}

\author{
Mohammad Vajdi ${ }^{a}$, Farhad Sadegh Moghanlou ${ }^{a}$, Fariborz Sharifianjazi $^{b}$
}

Mehdi Shahedi Asl ${ }^{a *}$, Mohammadreza Shokouhimehr ${ }^{c}$

${ }^{a}$ Department of Mechanical Engineering, University of Mohaghegh Ardabili, Ardabil, Iran

${ }^{b}$ Department of Materials and Metallurgical Engineering, Amirkabir University of Technology, PO Box 15875-4413, Tehran, Iran

${ }^{c}$ Department of Materials Science and Engineering, Research Institute of Advanced Materials, Seoul National University, Seoul 08826, Republic of Korea

\section{A B S T R A C T}

Numerical simulation is a powerful tool to predict the physical behavior of the designed devices. This method provides detailed information about the investigated phenomenon for each point of the device, which is generally challenging by experiments. Comsol Multiphysics can be utilized in a wide range of engineering fields. This software employs the finite element method (FEM) to solve the physical governing equations. Due to the importance of the heat transfer in advanced ceramics and the potential of the numerical methods to solve the related problems, the present article aims to provide a comprehensive review of the performed numerical research works using Comsol Multiphysics.

(C)2020 JCC Research Group.

Peer review under responsibility of JCC Research Group
A R T I CLE IN F O R M A T I O N

Article history:

Received 16 December 2019

Received in revised form 25 February 2020

Accepted 19 March 2020

Keywords:

Advanced ceramics

Numerical simulation

Comsol Multiphysics

Heat transfer

Table of contents

1. Introduction.

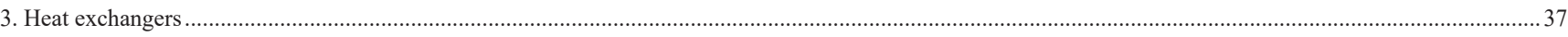

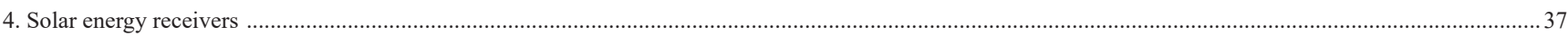

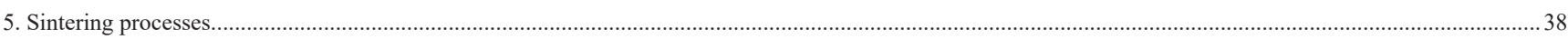

6. Turbine blades

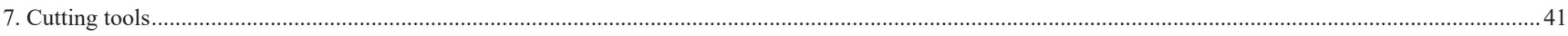

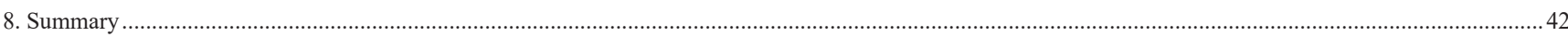

\section{Introduction}

Thermal systems are generally designed based on three objectives: enhancing system thermal efficiency [1-3], ensuring safety, and increasing service lifespan [4]. Selecting suitable working conditions, and the choice of materials, e.g. thermal systems, engine design, tool manufacturing, electronic devices, and biomechanics instruments are the important designing parameters $[5,6]$. Advanced ceramics with interesting thermomechanical properties are proven promising materials for the harsh condition applications of high temperatures or corrosive media. These materials have wide applications in aerospace, thermal systems, automotive technology, and manufacturing processes [7-10].
Ceramics are generally brittle and this is problematic in the case of impact or thermal shock. This issue needs to be considered with all aspects to avoid undesirable problems. Obtaining detail information about the physical characteristics of a designed device is a problematic issue, and in some cases, it seems to be impossible. Numerical simulation is a reliable method that provides detailed information at any point of the investigated case. The ability of the numerical methods has been verified in various fields of engineering, including biomechanics [11], energy [12-14], optics [15] micro, and nanotechnology [16, 17].

Comsol Multiphysics, as a commercial software package, provides a user-friendly environment to investigate a wide range of physical phenomena. The various embedded modules cover a wide range of physical 
Table 1.

Temperature-dependent thermal properties of some advanced ceramics.

\begin{tabular}{|c|c|c|c|}
\hline Material & $\mathrm{ZrB}_{2}$ & $\mathrm{TiB}_{2}[25-27]$ & $\mathrm{TiC}$ \\
\hline Heat capacity (J/Kg.K) & $\begin{array}{c}0.704+2.52 \times 10^{-5} \times T-80.2 \times T^{-1} \\
{[28]}\end{array}$ & $976+0.21 \times(T-273)-426 \times 10^{-0.008 \times(T-273)}$ & $\begin{array}{l}803+5.744 \times 10^{-2} \mathrm{~T} \\
-5.427 \times 10^{-5} \mathrm{~T}^{2}-23.685 \times 10^{6} / \mathrm{T}^{2}\end{array}$ \\
\hline Density $\left(\mathrm{Kg} / \mathrm{m}^{3}\right)$ & $6080[30]$ & $\begin{array}{l}77.3+\left(8270 \times 10^{-0.002 \times(T-273)}\right) \\
\times(410+(T-273))^{-1}\end{array}$ & $4930[31]$ \\
\hline $\begin{array}{l}\text { Thermal conductivity } \\
\qquad(\mathrm{W} / \mathrm{m} . \mathrm{K})\end{array}$ & $60.316+0.0041 \times T \quad[30]$ & $(0.0431 T+10.05) \times 10^{-8}$ & $9.8 \times 10^{-3} \mathrm{~T}+23.994[32]$ \\
\hline
\end{tabular}

analyses. The physical governing equations are designed to be solved using the finite element method. Numerous researches using Comsol have shown its ability to provide reliable results.

The present review article explores the heat transfer aspect of advanced ceramics using Comsol Multiphysics. By employing this software, it is possible to combine different active or passive methods to enhance heat transfer in thermal devices. In the active methods, external energy serves to increase the heat transfer rate. In the passive methods, variation in geometry or properties of applied materials augments the heat transfer [18, 19]. This review describes numerical simulations by Comsol Multiphysics covering various fields of heat exchangers, cutting tools, solar and energy systems, optical and manufacturing processes. The governing equations for each application are introduced and the results of the numerical simulation are presented.

\section{Laser drilling}

Among the various methods of fabrications, laser drilling of ceramics offers several advantages such as fast manufacturing rate, precise production, easy handling, high productivity, and low cost [20,21]. In this method, a high-intensity beam is concentrated on the subjected point to melt and vaporize the applied materials [22]. The transfer process in the heat-affected zone is an essential parameter since improper temperature distribution and consequent thermal stresses may cause damage to the products $[23,24]$. Local excessive thermal stress in the heating zone may result in surface and subsurface cracks. The detail information about the cutting process is needed to achieve a precise final product. Numerical simulations give detailed information about the heat transfer mechanism, temperature distribution, and phase change during ablation. It is also possible to insert the solid mechanic equations to acquire resulted thermal stresses, elastic and plastic strains, and the points capable of cracks formation.

The governing equations about the laser drilling process are as follow:

Time-dependent energy conversion equation:

$$
\rho C_{p} \frac{\partial T}{\partial t}=\nabla \cdot(k \nabla T)+Q
$$

where $\rho\left(\mathrm{kg} / \mathrm{m}^{3}\right)$ is density, $C_{p}(\mathrm{~J} / \mathrm{kg} . \mathrm{K})$ is heat capacity, and $k$ $(\mathrm{W} / \mathrm{m} . \mathrm{K})$ represents thermal conductivity. $Q\left(\mathrm{~W} / \mathrm{m}^{3}\right)$ belongs to the heat source inside the computational domain.

In numerical simulations, finding suitable temperature-dependent properties is very important. Some of the temperature-dependent thermal properties of several advanced ceramics are given in Table 1.

To simulate the thermal stresses and strains, the following equations are needed:
$\{\sigma\}=\frac{E\{\alpha\} \Delta T}{1-v}$

where $\{\sigma\}(\mathrm{Pa})$ is thermal stress, $E\{\alpha\}(\mathrm{Pa})$ represents Young's modulus, $\Delta T\left({ }^{\circ} \mathrm{C}\right)$ denotes temperature difference, and $v$ is Poisson's ratio.

The thermal strain vector is defined as:

$$
\left\{\varepsilon^{\text {th }}\right\}=\{\alpha\} \Delta T
$$

The heating effect of the applied laser can be used as a boundary source or boundary heat flux. The commonly used laser power is as [24]: $P_{s}=P_{0} \exp \left(-\frac{r^{2}}{w_{0}^{2}}\right)$

where $P_{s}$ is the intensity of applied laser power $\left(\mathrm{W} / \mathrm{m}^{2}\right), P_{0}$ is the peak power value, $r(\mathrm{~m})$ is the radial distance from the beam center, and the $w_{0}\left(\mathrm{~W} / \mathrm{m}^{2}\right)$ belongs to the radius, in which the amplitude is $1 / \mathrm{e}^{2}$.

The heat transfer to the surrounding occurs via all boundaries. Two mechanisms of convection and radiation dissipate the heat from the hot surfaces to the ambient. The convective heat transfer is introduced as Newton cooling law:

$q_{c}=h \cdot A \cdot \Delta T$

where $q_{c}(\mathrm{~W})$ denotes convective heat transfer, $A\left(\mathrm{~m}^{2}\right)$ is the heat transfer area, and $\Delta T\left({ }^{\circ} \mathrm{C}\right)$ is the temperature difference between the hot surface and ambient fluid. The radiation heat loss is as:

$q_{r}=\varepsilon \sigma A\left(T_{w}{ }^{4}-T_{\text {sur }}{ }^{4}\right)$

where $q_{\mathrm{r}}$ (W) is radiative heat transfer to the surroundings, $\varepsilon$ is the emissivity factor, and $\sigma_{\left(5.6704 \times 10^{-8}\left(\frac{W}{m^{2} K^{4}}\right)\right.}$ is Steffen-Boltzmann constant.

Bharatish et al. [24] evaluated the thermal residual stresses during the laser drilling of a workpiece made of alumina $\left(\mathrm{Al}_{2} \mathrm{O}_{3}\right)$. Some factors, e.g. laser power, frequency, hole diameter, and the scanning speed, were investigated. A series of time-dependent numerical simulations were performed to obtain the temperature distribution and predict the ther-

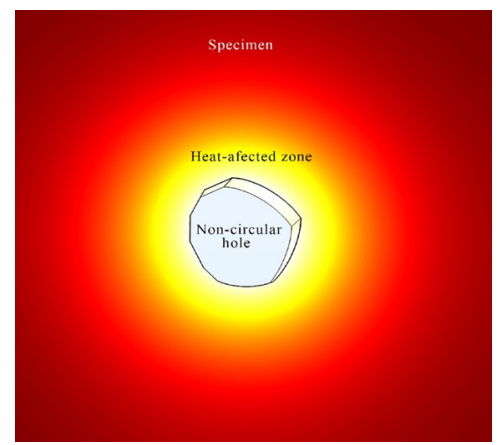

Fig. 1. Schematic of the heat-affected zone in the laser-drilled hole. 
mal stresses. The governing equations of transient heat transfer as well as stress-strain equations were solved using Comsol Multiphysics software. The results of simulations were used as validation for Raman thermal residual stresses. The captured scanning probe microscopy (SEM) images also confirmed that the cracks occurred at the heat-affected zone. The schematic of the hole and heat affected zone is shown in Fig. 1. Note that the laser-drilled hole is not circular.

Jia et al. [33] performed some experiments to investigate the micro-hole drilling in an $\mathrm{Al}_{2} \mathrm{O}_{3}$ ceramic. They used combined laser pulses of a millisecond, assisted a nanosecond (ns) pulse train, and reported that the used energy for drilling was decreased by order of magnitude. They simulated the drilling process using Comsol Multiphysics and showed that the elliptical keyhole ablated by nanosecond pulse train did not affect the circularity of the obtained hole.

Samant et al. [34] proposed a mathematical model to predict machined depth in laser cutting of silicon nitride $\left(\mathrm{Si}_{3} \mathrm{~N}_{4}\right)$ ceramic. They solved the heat transfer equation to obtain temperature distribution and considered the decomposition of the sample, evaporation because of high heat fluxes, and recoil pressure provoked expulsion of molten material. They reported a reasonable agreement between experimental data and presented a model for most of the cases. The discrepancy, in some cases, was attributed to errors in the measurement of experimental samples depth.

The machining of magnesia $(\mathrm{MgO})$ using pulsed Nd: YAG laser was simulated by Samant and Dahotre [35]. A mathematical model was proposed and the governing equations were solved using Comsol Multiphysics and finally, the results were compared with the experimental data.

The laser drilling of $\mathrm{SiC}$ ceramics was investigated by Samant et al. [36]. They claimed that the model is capable of providing required drilling pulses for a given depth of the sample. They also predicted the maximum needed recoil pressure for the melt pool during the drilling.

Wang et al. [37] reviewed the laser drilling of ceramics and referred to some researches performed using Ansys and Comsol. They concluded that the numerical simulations provide important parameters that are involved in the fabrication of high-quality products during the laser drilling of ceramics.

\section{Heat exchangers}

The application of ceramics as heat exchanger material has attracted more attention in media with high temperatures. Large deformations, oxidation danger, and metallurgical problems confine the application of metals at media with high temperatures or corrosive behavior [38, 39]. Ceramics generally have lower thermal conductivities compared to metals; however, some groups of ceramics such as $\mathrm{ZrB}_{2}, \mathrm{TiB}_{2}, \mathrm{SiC}, \mathrm{Si}_{3} \mathrm{~N}_{4}$, $\mathrm{AlN}$, and $\mathrm{BeO}$ show astonishing thermal conductivities. The application of these materials in the cooling of thermals systems, especially electrical processors, and optic systems have shown attractive heat transfer enhancement. An exploded view of AlN-made micro heat exchanger is shown in Fig. 2.

Fend et al. [41] performed some computations to simulate a gas/gas heat exchanger made of $\mathrm{SiC}$ at high working temperatures. They solved the continuity and momentum equations for fluid flows and the energy equation for both solid domain and fluid flow. The obtained results of the numerical simulation were in reasonable agreement with experimental data. Nekahi et al. [42] investigated the heat transfer and thermal effectiveness of a micro heat exchanger made of $\mathrm{TiB}_{2}-\mathrm{SiC}$ ceramic. The governing equations of fluid flow and heat transfer were discretized by the Galerkin method and solved using Comsol Multiphysics software. They compared their results by a micro heat exchanger made of alumina. They reported a $15.5 \%$ heat transfer enhancement using $\mathrm{TiB}_{2}-\mathrm{SiC}$ ceramic instead of $\mathrm{Al}_{2} \mathrm{O}_{3}$. This enhancement was attributed to the higher thermal conductivity of $\mathrm{TiB}_{2}-\mathrm{SiC}$ compared to $\mathrm{Al}_{2} \mathrm{O}_{3}$.

The governing equations for the simulation of single-phase (no phase change) heat exchangers are as follow:

Mass conservation equation for fluids:

$$
\begin{aligned}
& \frac{\partial \rho}{\partial t}+\nabla \cdot(\rho V)=0 \\
& \quad \text { Momentum equation for fluid flow: } \\
& \frac{\partial V}{\partial t}+v \cdot \nabla V=-\nabla P+\nabla \cdot\left(\mu\left(\nabla V+(\nabla V)^{T}\right)-\frac{2}{3} \mu(\nabla V) I\right. \\
& \quad \text { Energy conservation equation for the ceramic part: }
\end{aligned}
$$

$\rho C_{p} \frac{\partial T}{\partial t}=\nabla \cdot(k \nabla T)+Q$

Energy conservation equation for fluid flow:

$$
\rho C_{p}\left(\frac{\partial T}{\partial t}+(V . \nabla) T\right)=\nabla \cdot(k \nabla T)+Q
$$

Vajdi et al. [43] investigated a microchannel heat sink made by $\mathrm{ZrB}_{2}$ numerically. A conjugate heat transfer of solid domain and flow field was considered for simulation, and the governing equations were solved numerically by finite element method. They reported that at the high heat flux of $3.6 \mathrm{MW} / \mathrm{m}^{2}$, the maximum temperature did not exceed 360 K. Fattahi et al. [40] simulated the fluid flow and heat transfer in a micro heat exchanger made of AlN. Aluminum nitride has attractive properties such as remarkable thermal conductivity, high melting point, and astonishing elastic modulus $[44,45]$. As a result of the higher thermal conductivity of AlN compared to $\mathrm{Al}_{2} \mathrm{O}_{3}, 59 \%$ enhancement in the heat transfer was obtained.

\section{Solar energy receivers}

Ceramics are an inevitable part of energy harvesting systems nowadays. The thermoelectric refrigerators and generators [46, 47], and photovoltaic systems [48] benefit from the exclusive properties of ceramics. The application of ceramics in solar systems attracts more attention when the high-temperature conditions such as concentrated solar collectors and solar furnaces are encountered. Numerical methods can provide the temperature distribution at each point of the solar system. The obtained temperature gradients can be employed to evaluate consequent thermal stresses.

Ren et al. [49] carried out numerical simulations using Comsol on heat transfer of $\mathrm{SiC}$ made ceramic foam in a solar receiver. A schematic of a ceramic foam solar receiver is shown in Fig. 3. Parameters such as thermal conductivity effect, radiation distribution, and the time-dependent response of the proposed receiver were investigated. They found that the thicker the receiver dimension, the higher the efficiency of the system. However, they reported that thickening the receiver structure would increase the production costs. They also concluded that to avoid thermal stress based damages, the standard deviation must be adjusted to the highest possible value.

Wang et al. [50] investigated the thermal radiation in a solar receiver made of SiC. They solved the governing equations for both ceramics and fluid domains. They indicated the Nusselt number counter maps for involved parameters such as solid-fluid thermal conductivity ratio and conduction-radiation parameters. Fend et al. [51] investigated the thermal performance of a honeycomb structure used in a solar tower. Silicon carbide was considered as the material, and two numerical models of single-channel and porous medium were investigated. An experimental set-up was made and used as validation for the numerical results. A good agreement between experimental results and numerical simulation showed the capability of the proposed models. 


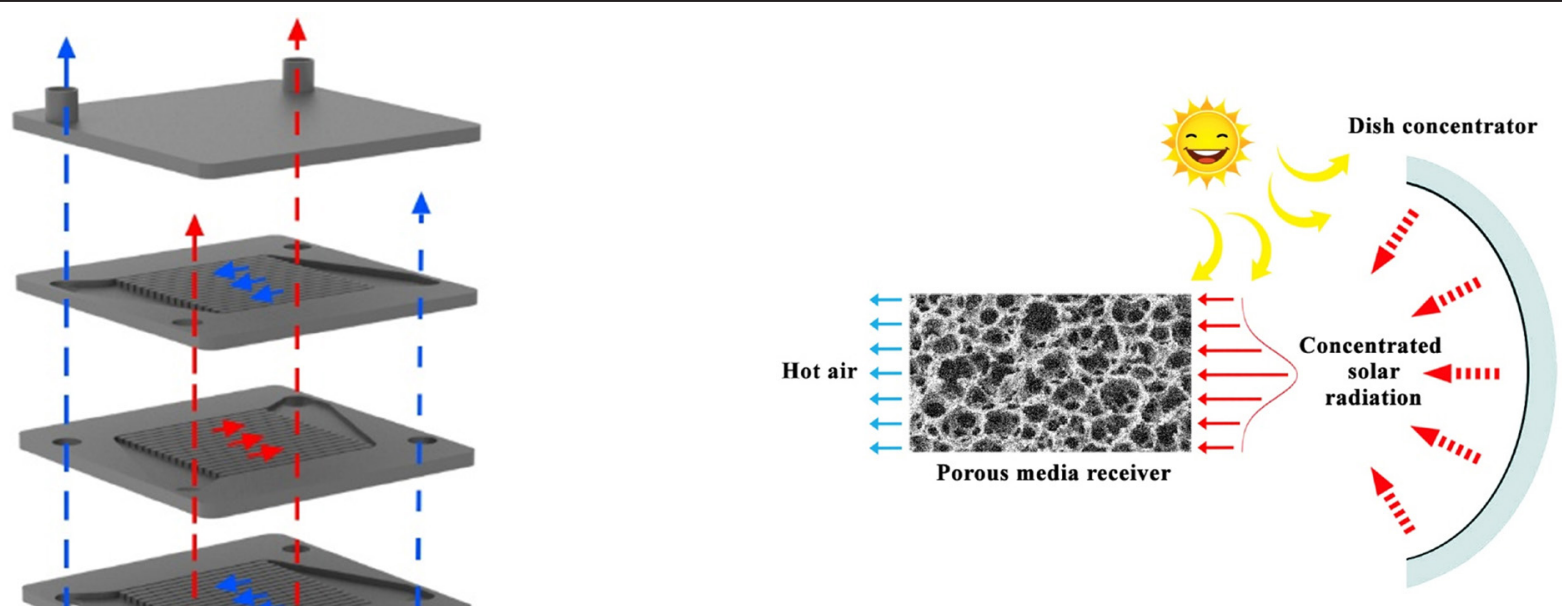

Fig. 3. Scheme of a ceramic foam solar receiver.

conduction and convection heating mechanisms, the maximum temperature did not exceed $1200{ }^{\circ} \mathrm{C}$ during the sintering. The authors stated that radiation heat transfer is dominant in the rapid sintering of ceramics.

Wei et al. [53] studied the spark plasma sintering (SPS) of $\mathrm{ZrC}$ by Comsol Multiphysics. They obtained experimental data of the sintering process and used them to validate the numerical simulations. The 3D sample and die were modeled in a 2D axisymmetric domain to reduce the simulation time. The sample fabricated by the spark plasma sintering showed higher relative density compared to the one obtained by hot pressing (HP). The proposed numerical method could predict the grain size and the consequent relative density, as shown in Fig. 5. Temperature distribution in the sample, die, and punches is given in Fig. 6, which shows the place of maximum temperature at the punches.

Wei et al. [54] studied the capability of SPS in producing net-shaped samples such as ring-shaped or annular ones made of ultrahigh temperature ceramics (UHTCs), which are more complex compared to a solid cylinder or disk. Particular types of graphite die were introduced to consolidate the $\mathrm{ZrC}$ powder in the desired shape, as shown in Fig. 7. The numerical simulation by Comsol was used to predict the porosity of an as-sintered annular sample verified by experimental results (Fig. 8). Von Mises stress distribution at different time steps was also obtained. The results showed that stress value at the specimen/mandrel interface was greater than that at the die/specimen interface.

Numerical simulation of heat transfer during SPS of different UHTCs was also investigated. Heat transfer mechanism and temperature distribution during the consolidating of the $\mathrm{ZrB}_{2}$ powder were studied by Sakkaki et al. [55]. The studied sample was a disk, and heat generation inside the sample was modeled by the Joule heating effect. Since $\mathrm{ZrB}_{2}$ is electrically conductive, they compared their results with the study of Pavia et al. [56], who modeled the $\mathrm{SPS}$ of $\mathrm{Al}_{2} \mathrm{O}_{3}$ as an electrical insulator obtained with no cracks. The heating rate was in the order of hundreds per minute, and the simulations showed that by considering only the

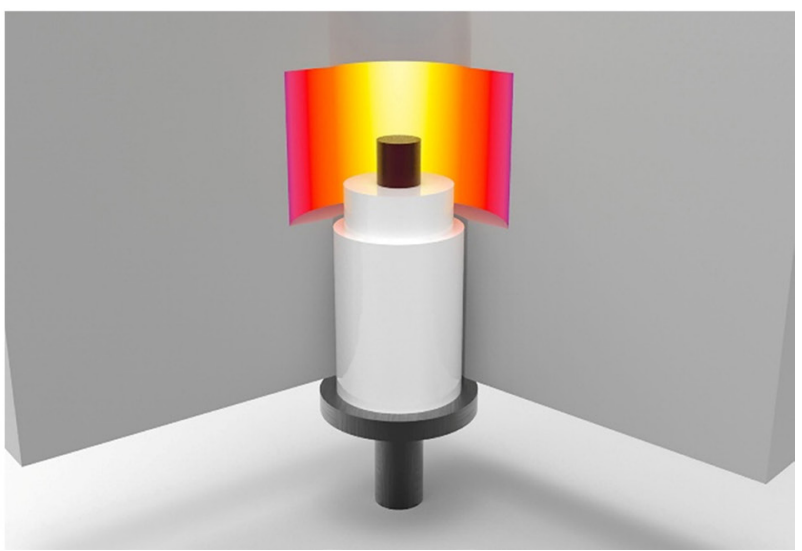

Fig. 4. Schematic of the sample and the furnace used by Salamon et al. Reproduced with permission [52]. 


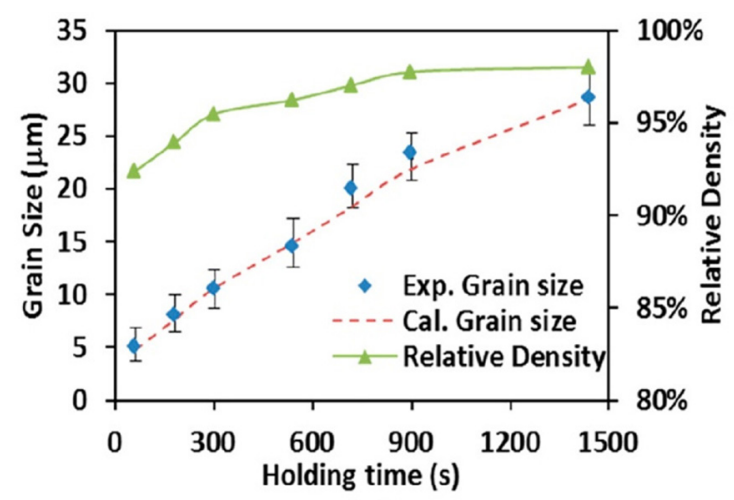

Fig. 5. Numerical simulation validation based on grain size and relative density of $\mathrm{ZrC}$ sample. Reproduced with permission [53].

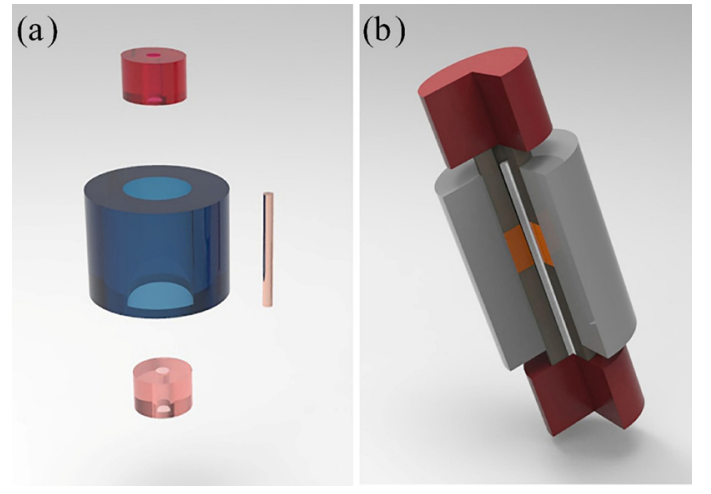

Fig. 7. (a) Exploded view, and (b) assembled form of the schematic of the SPS facility for a ring-shaped sample sintering according to the ref [54].Reproduced with permission [53].

(a)
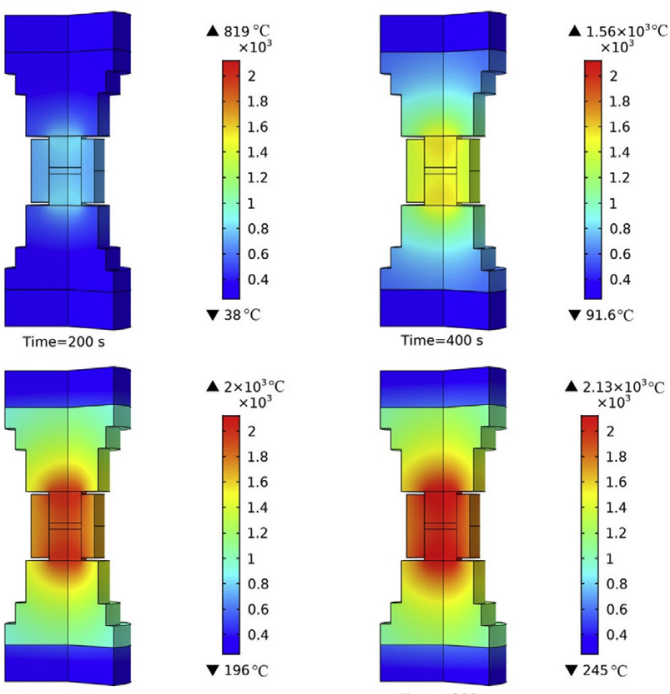

(b)

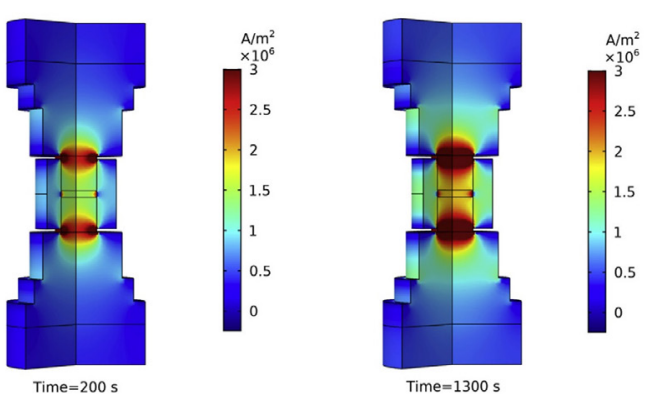

Fig. 9. (a) Temperature contour, and (b) current density contour during SPS of ZrB2. Reproduced with permission [55].

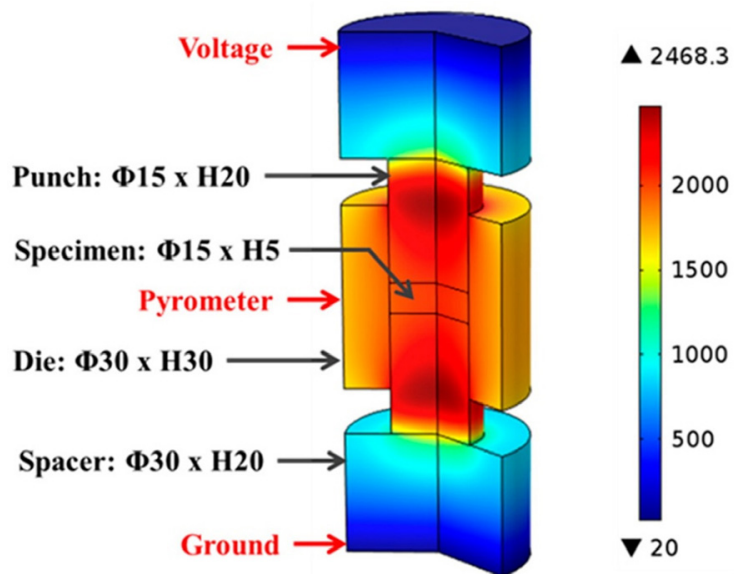

Fig. 6. Temperature $\left({ }^{\circ} \mathrm{C}\right)$ distribution in the SPS facility and $\mathrm{ZrC}$ sample. Reproduced with permission [53].

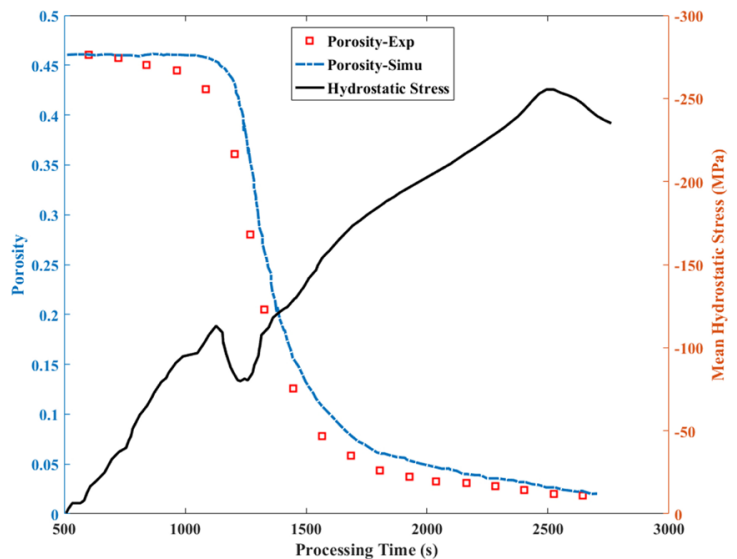

Fig. 8. Comparison of numerical and experimental results of SPS modeling of ZrC. Reproduced with permission [54].

ceramic.

Two sets of governing equations, i.e. electric charge, and energy conservation equations were solved to find the temperature and electric current distribution.

The direct electric (DC) Maxwell's equation is as [57]:

$\nabla J=\nabla(\sigma E)=\nabla(-\sigma \nabla U)=0$

Where $J\left(A / m^{2}\right), E(V / m), U(V)$ and $\sigma(S / m)$ are responsible for the electric current density, the electric field, the electric potential, and the electrical conductivity of the used materials, respectively.

Concerning the symmetrical shape of the simulated domain, Sakkaki et al. [55] used the axisymmetric form of governing equations. They used the energy conservation equation in the cylindrical form introduced as:

$\rho C_{p} \frac{\partial T}{\partial t}=\frac{1}{r} \frac{\partial}{\partial r}\left(r k_{r} \frac{\partial T}{\partial r}\right)+\frac{1}{z} \frac{\partial}{\partial z}\left(r k_{z} \frac{\partial T}{\partial z}\right)+q_{i}$

where $k_{r}$ and $k_{z}$ belong to the thermal conductivity in $r$ and $z$ directions, respectively. The heat generation as a result of Joule heating is shown by $q_{i}$ which is defined as:

$q_{i}=J . E$

They also used the cylindrical form of the electric current equation as:

$\frac{1}{r} \frac{\partial\left(r i_{r}\right)}{\partial r}+\frac{\partial i_{z}}{\partial z}=0$

where $i_{r}$ and $i_{z}$ indicate the electrical current densities per volume in the $r$ and $z$ directions, respectively.

They used root-mean-square (RMS) voltage as [56]: 
(a)

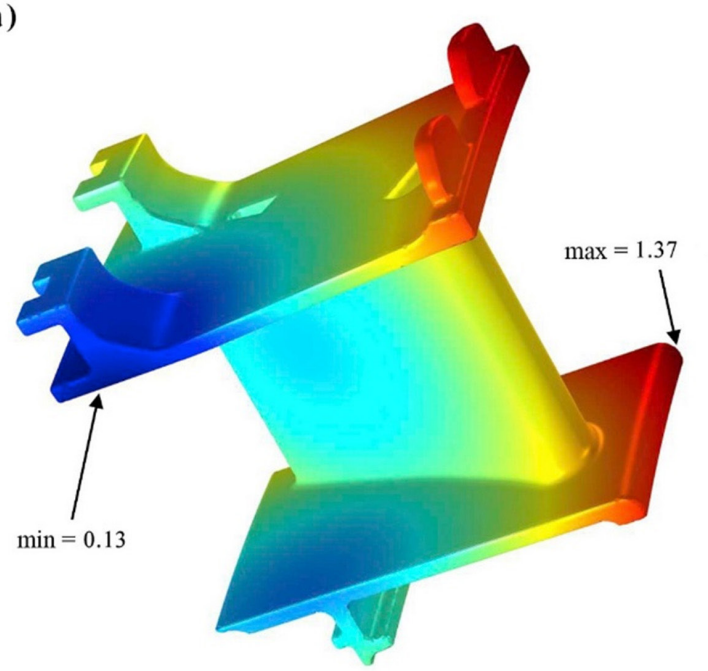

(b)

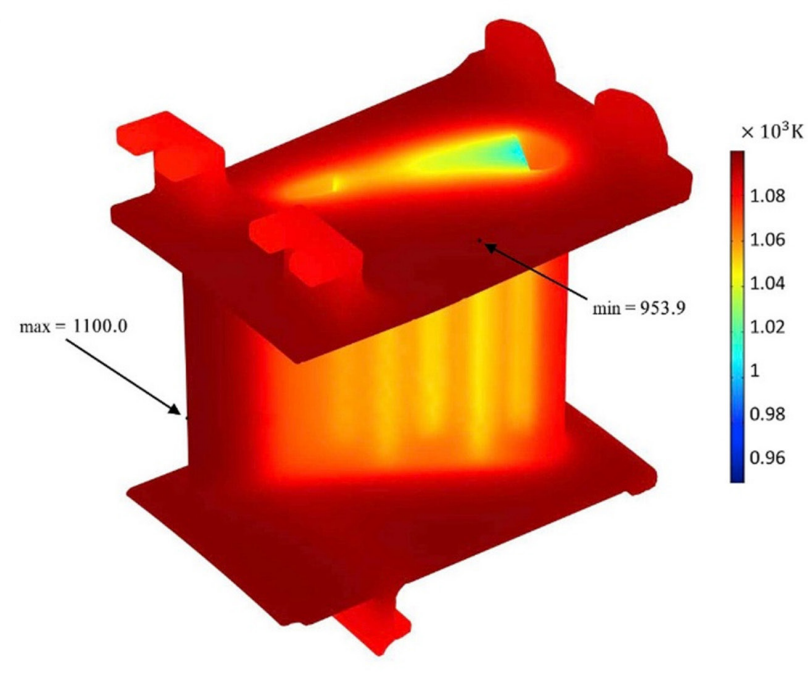

Fig. 10. (a) Displacement, and (b) temperature contours of a gas turbine stator blade made of $\mathrm{ZrB}_{2}$ ultra high temperature ceramic. Reproduced with permission [60].

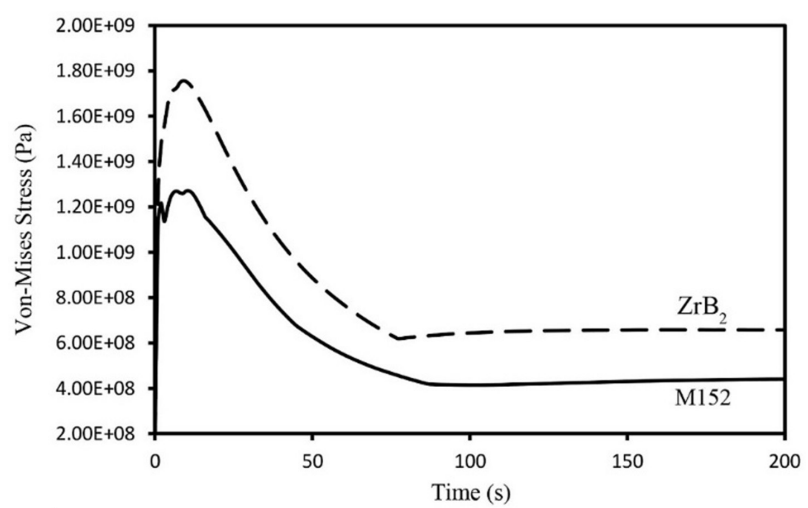

Fig. 11. Von-Mises stress vs. time for gas turbine stator blades made of $\mathrm{ZrB}_{2}$ ceramic and M152 superalloy. Reproduced with permission [60].
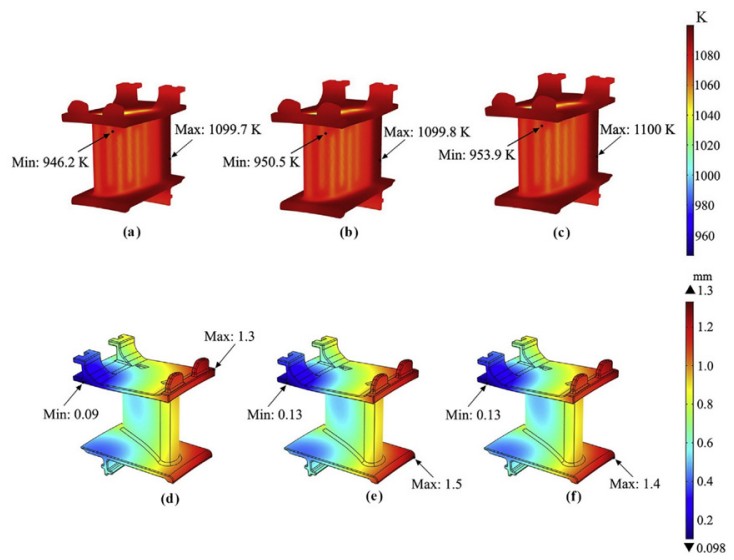

Fig. 12. Temperature contours of turbine stator blades made of (a) $\mathrm{HfB}_{2}$, (b) $\mathrm{TiB} 2$, and (c) ZrB2. Displacement contours of the turbine stator blades made of (d) $\mathrm{HfB}_{2}$, (e) $\mathrm{TiB}_{2}$, and (f) $\mathrm{ZrB}_{2}$ UHTCs. Reproduced with permission [61].

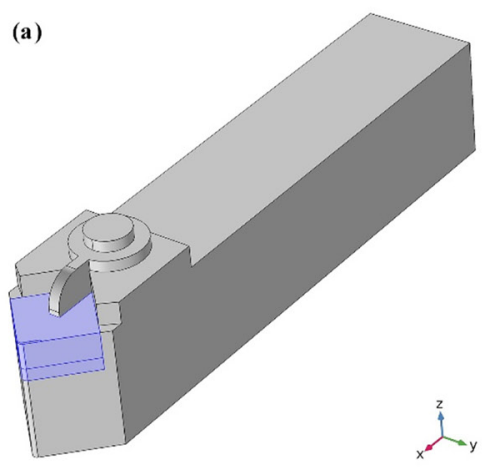

(b)

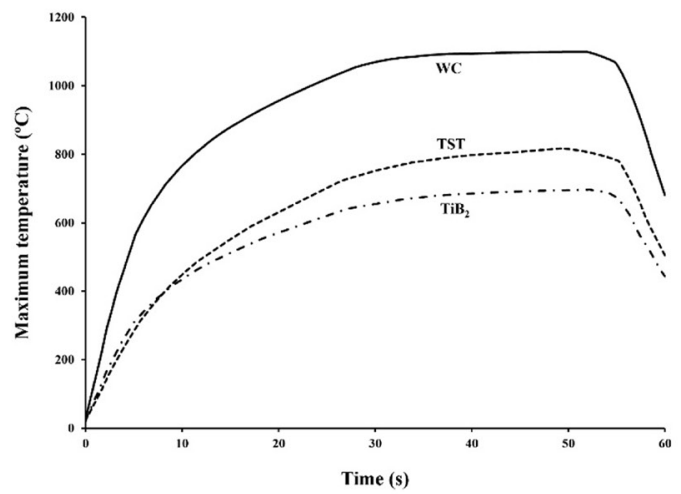

Fig. 13. (a) Cutting tool model in Comsol, and (b) obtained maximum temperature vs. time for different ceramics. Reproduced with permission [62].

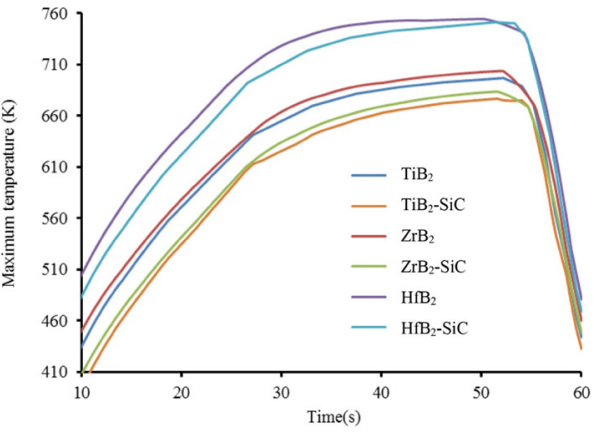

Fig. 14. Effect of $\mathrm{SiC}$ addition on the maximum temperature of diboride made cutting tools. Reproduced with permission [63].

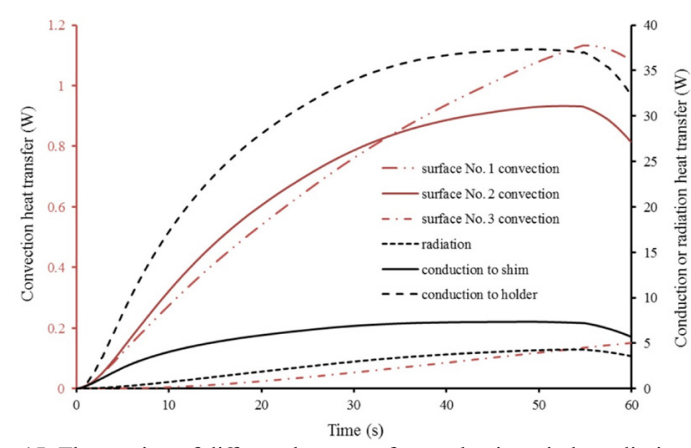

Fig. 15. The portion of different heat transfer mechanisms in heat dissipation from the $\mathrm{HfB}_{2}$ made cutting tool. Reproduced with permission [63]. 
(a)

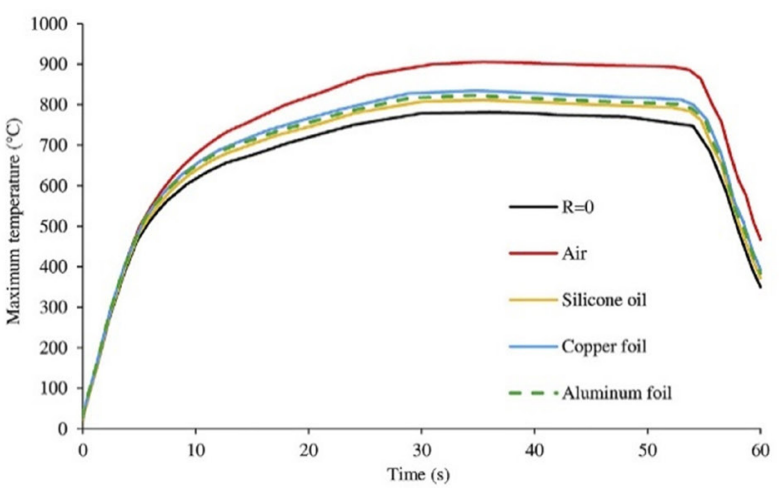

(b)

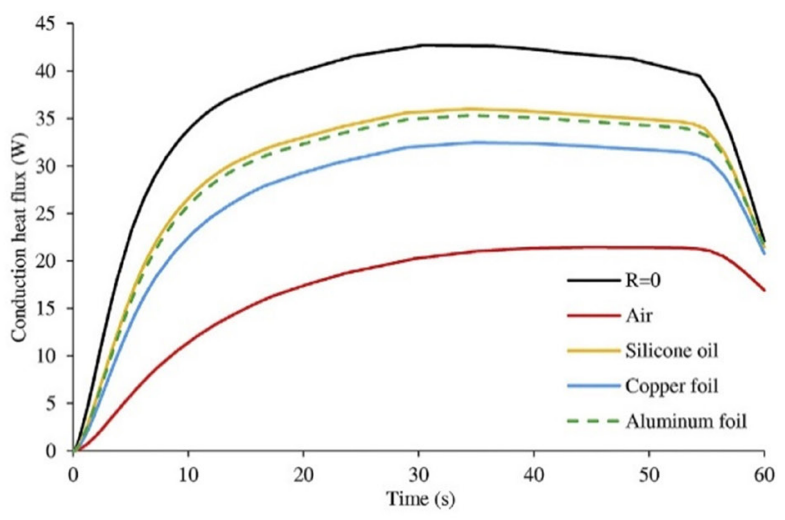

Fig. 16. The effect of different TCRs on the (a) maximum temperature, and (b) heat conduction to the holder and shim. Reproduced with permission [4].

$U_{R M S}=\sqrt{\frac{1}{P} \int_{t-T}^{t} u^{2}(\tau) d \tau}$

where $u$ is the instantaneous voltage, and $P$ is the AC voltage period.

Sakkaki et al. [55] showed that the location of the maximum current density and the maximum temperature are different. The maximum temperature was located at the sample center, while the maximum current density was at the spacer/punch interface due to its minimum area (Fig. 9). The same simulation was performed for $\mathrm{TiC}$ [58] and $\mathrm{TiB}_{2}[59]$. The results showed that for samples with higher thermal conductivities, a more uniform temperature distribution could be obtained, which has a direct effect on the microstructure of the as-sintered sample.

\section{Turbine blades}

Gas turbine stator blades experience no centrifugal force and consequent tensile stresses; therefore, ceramics can be good candidates for manufacturing gas turbine stator blades [60]. Sadegh et al. [60] employed Comsol for heat transfer and thermal stress modeling in a gas turbine stator blade made of $\mathrm{ZrB}_{2}$. Governing equations of heat transfer and stress-strain were considered as equations 1-3. The convective heat transfer coefficient was considered for inner cooling ducts. Since the outer surface encounters hot gases, its effect was considered applying the convective heat transfer coefficient.

The temperature distribution and displacement due to thermal stresses were defined as shown in Fig. 10. The results showed that the $\mathrm{ZrB}_{2}$ made stator blade acquired considerably lower displacement but higher stress compared to M152 superalloy (Table 2, Fig. 11). Employment of UHTCs like $\mathrm{TiB}_{2}$ and $\mathrm{HfB}_{2}$ as the gas turbine stator blades were studied by Vaferi et al. [27] and Nekahi et al. [61], respectively. Vaferi et al. [27] analyzed the thermal stress in $\mathrm{TiB}_{2}$ made gas turbine stator blade with Comsol and defined the fatigue possibility of the blade using the Coulomb-Mohr theory. They reported that the blade could tolerate the thermal stresses without failure with the safety factor of 2.4. Nekahi et al. [61] also used Comsol for simulating the heat transfer and calculating the consequent thermal stresses. They compared the temperature

\section{Table 2.}

Comparison of maximum and minimum displacements for turbine blades made of M152 superalloy and ZrB2 UHTC [61].

\begin{tabular}{ccc}
\hline Material & $\begin{array}{c}\text { Maximum dis- } \\
\text { placement }(\mathrm{mm})\end{array}$ & $\begin{array}{c}\text { Minimum dis- } \\
\text { placement }(\mathrm{mm})\end{array}$ \\
\hline M152 superalloy & 2.27 & 0.15 \\
$\mathrm{ZrB}_{2}$ ceramic & 1.37 & 0.13 \\
\hline
\end{tabular}

and displacement distribution in the blades made of zirconium, titanium, and hafnium diborides (Fig. 12). Employment of $\mathrm{HfB}_{2}$ as turbine blade material resulted in the lowest displacement and the highest thermal stress values. It was also declared that all three UHTCs could tolerate the applied stresses and no failure predicted based on the Coulomb-Mohr theory.

\section{Cutting tools}

Ceramics, such as $\mathrm{TiB}_{2}$ and $\mathrm{WC}$, are widely used as cutting tools due to their excellent hardness $[62,63]$. Temperature control and cooling of a cutting device play an essential role in the productivity and quality of the machined surface [63]. Modeling and measuring temperature distribution in cutting tools have attracted much attention lately [4, 64]. Vajdi et al. [62] fabricated a novel $\mathrm{TiB}_{2}$-based composite using $\mathrm{SiC}$ and metallic $\mathrm{Ti}$ as reinforcements and measured the thermal properties of fabricated material. Comsol-assisted numerical simulation was applied to determine the temperature distribution in the tool, especially the maximum temperature of the tool tip. They used the heat diffusion equation (Eq. 1) for the solid parts and convection-radiation equation, equations 5 and 6 , for heat losses from the walls. The geometry of the cutting tool and the obtained maximum temperature versus time for three different ceramics is demonstrated in Fig. 13. They concluded that the novel $\mathrm{TiB}_{2}-\mathrm{SiC}-\mathrm{Ti}$ (TST) composite showed better thermal performance than WC made common tools.

Heat transfer in the cutting tools made of different diborides and the effect of $\mathrm{SiC}$ addition on the performance of ceramic cutting tools were studied by Sadegh et al. [63]. They conducted a numerical study by Comsol and showed that $\mathrm{SiC}$ addition to monolithic ceramics improved their thermal performance. As shown in Fig. 14, the maximum temperature of the cutting tool during a 50 -second engagement reduced by adding $20 \mathrm{vol} \% \mathrm{SiC}$ to the monolithic diborides. The tool transfers the generated heat to the surroundings by radiation, convection, and conduction. To determine the dominant heat transfer mechanism, the authors analyzed each heat transfer mechanism and its portion in the total heat dissipation. The results showed that the most important heat dissipation mechanism was radiation and then conduction to the holder (Fig. 15).

The modeling of the effect of thermal contact resistance (TCR) on the thermal performance of a WC-made cutting tool was performed by Sakkaki et al. [4] employing Comsol Multiphysics. TCR plays an essential role in the heat flow and acts as a barrier; therefore, TCR reduction can ease the heat flow. They showed that an ideal case with no TCR could reduce the maximum temperature considerably, although it was almost impossible due to its high fabrication cost. Moreover, usual methods such as applying silicone or metal foils were proposed, and their effect on heat flow was simulated numerically. In Fig. 16, the effect of different cases on maximum temperature and heat conduction versus 
cutting time is shown.

One of the proposed methods to protect the cutting tools from high temperatures is coating their surfaces. Heat transfer and temperature distribution modeling of a coated carbide turning cutting tool was modeled by Ferreira et al. [65]. They used the heat generation at the tool tip according to the results of Brito et al. [64] and obtained the temperature contours in the tool utilizing Comsol Multiphysics. The effect of using TiN and $\mathrm{Al}_{2} \mathrm{O}_{3}$ as coating materials and their thickness on the thermal performance of the tool was studied. The results showed that $\mathrm{Al}_{2} \mathrm{O}_{3}$ could protect the WC made cutting tool more than TiN coating as a result of its lower thermal conductivity in comparison with TiN.

\section{Summary}

Numerical simulations are able to provide the detailed information about the physical behavior of the advanced ceramics in various engineering fields. Comsol Multiphysics, as a numerical simulation pack is a powerful software, which covers a wide range of physical phenomena and provide reliable results. In the present paper, a comprehensive review of numerical studies utilizing Comsol Multiphysics about the heat transfer behavior of some advanced ceramics was carried out. The advantages of advanced ceramics were discussed. Their applications in various fields of engineering products and processes were explained. The performed simulations in laser drilling, heat exchangers, cutting tools, sintering processes, solar systems, and other thermal devices were reviewed. The basic governing equations for each case were given, and some obtained results were depicted. This review article covered the capability of the Comsol Multiphysics to provide reliable results.

\section{Acknowledgments}

The authors received no financial support for the research, authorship and/or publication of this article.

\section{Conflict of Interest}

All authors declare no conflicts of interest in this paper.

\section{REFERENCES}

[1] T. Gholizadeh, M. Vajdi, H. Rostamzadeh, A new trigeneration system for power, cooling, and freshwater production driven by a flash-binary geothermal heat source, Renewable Energy 148 (2020) 31-43.

[2] T. Gholizadeh, M. Vajdi, H. Rostamzadeh, Freshwater and cooling production via integration of an ethane ejector expander transcritical refrigeration cycle and a humidification-dehumidification unit, Desalination 477 (2020) 114259.

[3] T. Gholizadeh, M. Vajdi, H. Rostamzadeh, Exergoeconomic optimization of a new trigeneration system driven by biogas for power, cooling, and freshwater production, Energy Conversion and Management 205 (2020) 112417.

[4] M. Sakkaki, F. Sadegh Moghanlou, M. Vajdi, F. Pishgar, M. Shokouhimehr, M. Shahedi Asl, The effect of thermal contact resistance on the temperature distribution in a WC made cutting tool, Ceramics International 45(17, Part A) (2019) 22196-22202.

[5] S.K. Yekani, E. Abdi Aghdam, F. Sadegh Moghanlou, Performance Response of a Spark Ignition Engine to Adding Natural Gas to Gasoline on Lean-Burn Condition in 10 Compression Ratio, Modares Mechanical Engineering 20(6) (2020) 1691-1699.

[6] S.K. Yekani, E. Abdi Aghdam, F. Sadegh Moghanlo, Experimental study and comparison of the exhaust gas emissions response of a spark ignition engine to adding natural gas to gasoline in lean-burn condition, Int. J. Ind. Math. (2020).

[7] F. Sadegh Moghanlou, S. Nekahi, M. Vajdi, Z. Ahmadi, A. Motallebzadeh, A. Shokouhimehr, M. Shokouhimehr, S. Jafargholinejad, M. Shahedi Asl, Effects of graphite nano-flakes on thermal and microstructural properties of TiB2-SiC composites, Ceramics International 46(8, Part B) (2020) 11622-11630.

[8] S. Nekahi, F. Sadegh Moghanlou, M. Vajdi, Z. Ahmadi, A. Motallebzadeh, M. Shahedi Asl, Microstructural, thermal and mechanical characterization of $\mathrm{TiB}_{2}-$ $\mathrm{SiC}$ composites doped with short carbon fibers, International Journal of Refractory Metals and Hard Materials 82 (2019) 129-135.
[9] M. Vajdi, F. Sadegh Moghanlou, Z. Ahmadi, A. Motallebzadeh, M. Shahedi Asl, Thermal diffusivity and microstructure of spark plasma sintered TiB2SiCTi composite, Ceramics International 45(7, Part A) (2019) 8333-8344.

[10] M. Namazizadeh, M. Talebian Gevari, M. Mojaddam, M. Vajdi, Optimization of the splitter blade configuration and geometry of a centrifugal pump impeller using design of experiment, Journal of Applied Fluid Mechanics 13(1) (2020) 89101.

[11] Z. Hajati, F.S. Moghanlou, M. Vajdi, S.E. Razavi, S. Matin, Fluid-structure interaction of blood flow around a vein valve, BioImpacts: BI 10(3) (2020) 169.

[12] T. Gholizadeh, M. Vajdi, H. Rostamzadeh, A new biogas-fueled bi-evaporator electricity/cooling cogeneration system: Exergoeconomic optimization, Energy Conversion and Management 196 (2019) 1193-1207.

[13] T. Gholizadeh, M. Vajdi, F. Mohammadkhani, Thermodynamic and thermoeconomic analysis of basic and modified power generation systems fueled by biogas, Energy conversion and management 181 (2019) 463-475.

[14] T. Gholizadeh, M. Vajdi, H. Rostamzadeh, Energy and exergy evaluation of a new bi-evaporator electricity/cooling cogeneration system fueled by biogas, Journal of cleaner production 233 (2019) 1494-1509.

[15] S. Singh, R.S. Kaler, Performance analysis of evanescent wave absorption plasmonic optical sensor with COMSOL FEM method simulation, Procedia Computer Science 125 (2018) 376-381.

[16] R.S. Jakati, K.B. Balavalad, B.G. Sheeparamatti, Comparative analysis of different micro-pressure sensors using comsol multiphysics, in: 2016 Int. Conf. Electr. Electron. Commun. Comput. Optim. Tech., IEEE, 2016: pp. 355-360.

[17] H. Fu, M. Zhang, J. Ding, J. Wu, Y. Zhu, H. Li, Q. Wang, C. Yang, A high sensitivity D-type surface plasmon resonance optical fiber refractive index sensor with graphene coated silver nano-columns, Optical Fiber Technology 48 (2019) 34-39. [18] M. Sakkaki, F. Sadegh Moghanlou, S. Parvizi, H. Baghbanijavid, A. Babapoor, M. Shahedi Asl, Phase change materials as quenching media for heat treatment of 42CrMo4 steels, Journal of Central South University 27(3) (2020) 752-761.

[19] F.S. Moghanlou, A.S. Khorrami, E. Esmaeilzadeh, H. Aminfar, Experimental study on electrohydrodynamically induced heat transfer enhancement in a minichannel, Experimental Thermal and Fluid Science 59 (2014) 24-31.

[20] M. Vajdi, F.S. Moghanlou, F. Sharifianjazi, M.S. Asl, M. Shokouhimehr, A review on the Comsol Multiphysics studies of heat transfer in advanced ceramics, Journal of Composites and Compounds 2(2) (2020) 35-43.

[21] A.S. Kuar, B. Doloi, B. Bhattacharyya, Modelling and analysis of pulsed Nd: YAG laser machining characteristics during micro-drilling of zirconia ( $\mathrm{ZrO} 2)$, International Journal of Machine Tools and Manufacture 46(12-13) (2006) 13011310 .

[22] K. Salonitis, A. Stournaras, G. Tsoukantas, P. Stavropoulos, G. Chryssolouris, A theoretical and experimental investigation on limitations of pulsed laser drilling, Journal of Materials Processing Technology 183(1) (2007) 96-103.

[23] B.S. Yilbas, C. Karatas, A.F.M. Arif, B.J.A. Aleem, Laser control melting of alumina surfaces and thermal stress analysis, Optics \& Laser Technology 43(4) (2011) 858-865.

[24] A. Bharatish, H.N.N. Murthy, G. Aditya, B. Anand, B.S. Satyanarayana, M. Krishna, Evaluation of thermal residual stresses in laser drilled alumina ceramics using Micro-Raman spectroscopy and COMSOL Multiphysics, Optics \& Laser Technology 70 (2015) 76-84.

[25] C. Subramanian, T.S.R.C. Murthy, A.K. Suri, Synthesis and consolidation of titanium diboride, International Journal of Refractory Metals and Hard Materials 25(4) (2007) 345-350.

[26] A.D. McLeod, J.S. Haggerty, D.R. Sadoway, Electrical resistivities of monocrystalline and polycrystalline $\mathrm{TiB}_{2}$, Journal of the American ceramic Society 67(11) (1984) 705-708.

[27] K. Vaferi, S. Nekahi, M. Vajdi, F.S. Moghanlou, M. Shokouhimehr, A. Motallebzadeh, J. Sha, M.S. Asl, Heat transfer, thermal stress and failure analyses in a TiB2 gas turbine stator blade, Ceramics International 45(15) (2019) 19331-19339. [28] F. Nakamori, Y. Ohishi, H. Muta, K. Kurosaki, K.-i. Fukumoto, S. Yamanaka, Mechanical and thermal properties of bulk ZrB2, Journal of Nuclear Materials 467 (2015) 612-617.

[29] M. Le Flem, A. Allemand, S. Urvoy, D. Cédat, C. Rey, Microstructure and thermal conductivity of Mo-TiC cermets processed by hot isostatic pressing, Journal of Nuclear Materials 380(1-3) (2008) 85-92.

[30] E. Zapata-Solvas, D.D. Jayaseelan, H.-T. Lin, P. Brown, W.E. Lee, Mechanical properties of $\mathrm{ZrB}_{2}$-and $\mathrm{HfB}_{2}$-based ultra-high temperature ceramics fabricated by spark plasma sintering, Journal of the European Ceramic Society 33(7) (2013) 1373-1386.

[31] N. Durlu, Titanium carbide based composites for high temperature applications, Journal of the European Ceramic Society 19(13-14) (1999) 2415-2419.

[32] W.S. Williams, The thermal conductivity of metallic ceramics, Jom $50(6)$ 
(1998) 62-66.

[33] X. Jia, G. Zhu, Y. Zhang, Y. Chen, H. Wang, P. Shan, K. Aleksei, X. Zhu, Laser processing of alumina ceramic by spatially and temporally superposing the millisecond pulse and nanosecond pulse train, Optics Express 28(1) (2020) 676-684.

[34] A.N. Samant, N.B. Dahotre, Ab initio physical analysis of single dimensional laser machining of silicon nitride, Advanced Engineering Materials 10(10) (2008) 978-981.

[35] A.N. Samant, N.B. Dahotre, An integrated computational approach to single-dimensional laser machining of magnesia, Optics and lasers in engineering 47(5) (2009) 570-577.

[36] A.N. Samant, C. Daniel, R.H. Chand, C.A. Blue, N.B. Dahotre, Computational approach to photonic drilling of silicon carbide, The International Journal of Advanced Manufacturing Technology 45(7) (2009) 704-713.

[37] H. Wang, H. Lin, C. Wang, L. Zheng, X. Hu, Laser drilling of structural ceramics - A review, Journal of the European Ceramic Society 37(4) (2017) 11571173.

[38] A. Traverso, A.F. Massardo, R. Scarpellini, Externally fired micro-gas turbine: modelling and experimental performance, Applied Thermal Engineering 26(16) (2006) 1935-1941

[39] K.M. Deen, M.A. Virk, C.I. Haque, R. Ahmad, I.H. Khan, Failure investigation of heat exchanger plates due to pitting corrosion, Engineering Failure Analysis 17(4) (2010) 886-893.

[40] M. Fattahi, K. Vaferi, M. Vajdi, F.S. Moghanlou, A.S. Namini, M.S. Asl, Aluminum nitride as an alternative ceramic for fabrication of microchannel heat exchangers: a numerical study, Ceramics International 46(8) (2020) 11647-11657. [41] O. Smirnova, T. Fend, D. Schöllgen, Numeric modeling of a compact high temperature heat exchanger., in: COMSOL Coference Proceedings, (2011).

[42] S. Nekahi, M. Vajdi, F.S. Moghanlou, K. Vaferi, A. Motallebzadeh, M. Özen, U. Aydemir, J. Sha, M.S. Asl, $\mathrm{TiB}_{2}-\mathrm{SiC}-b a s e d$ ceramics as alternative efficient micro heat exchangers, Ceramics International 45(15) (2019) 19060-19067.

[43] M. Vajdi, F.S. Moghanlou, E.R. Niari, M.S. Asl, M. Shokouhimehr, Heat transfer and pressure drop in a $\mathrm{ZrB}$, microchannel heat sink: a numerical approach, Ceramics International 46(2) (2020) 1730-1735

[44] G. Hansdah, B.K. Sahoo, Pyroelectric property of binary nitrides (AIN, GaN and InN), International Journal of Thermophysics 40(2) (2019) 1-10

[45] G.A. Slack, R.A. Tanzilli, R.O. Pohl, J.W. Vandersande, The intrinsic thermal conductivity of AIN, Journal of Physics and Chemistry of Solids 48(7) (1987) 641-647.

[46] F.-D. Börner, M. Schreier, B. Feng, W. Lippmann, H.-P. Martin, A. Michaelis, A. Hurtado, Development of laser-based joining technology for the fabrication of ceramic thermoelectric modules, Journal of Materials Research 29(16) (2014) 1771-1780.

[47] S. Shittu, G. Li, X. Zhao, X. Ma, Y.G. Akhlaghi, E. Ayodele, High performance and thermal stress analysis of a segmented annular thermoelectric generator, Energy Conversion and Management 184 (2019) 180-193.

[48] Y. Du, W. Tao, Y. Liu, J. Jiang, H. Huang, Heat transfer modeling and temperature experiments of crystalline silicon photovoltaic modules, Solar Energy 146 (2017) 257-263.

[49] Y. Ren, H. Qi, J. Shi, Q. Chen, Y. Wang, L. Ruan, Thermal performance characteristics of porous media receiver exposed to concentrated solar radiation, Journal of Energy Engineering 143(5) (2017) 04017013.

[50] P. Wang, K. Vafai, D.Y. Liu, Analysis of radiative effect under local thermal non-equilibrium conditions in porous media-application to a solar air receiver, $\mathrm{Nu}-$ merical Heat Transfer, Part A: Applications 65(10) (2014) 931-948.

[51] T. Fend, P. Schwarzbözl, O. Smirnova, D. Schöllgen, C. Jakob, Numerical investigation of flow and heat transfer in a volumetric solar receiver, Renewable energy 60 (2013) 655-661.

[52] D. Salamon, R. Kalousek, J. Zlámal, K. Maca, Role of conduction and convection heat transfer during rapid crack-free sintering of bulk ceramic with low thermal conductivity, Journal of the European Ceramic Society 36(12) (2016) 2955-2959.

[53] X. Wei, C. Back, O. Izhvanov, C.D. Haines, E.A. Olevsky, Zirconium carbide produced by spark plasma sintering and hot pressing: densification kinetics, grain growth, and thermal properties, Materials 9(7) (2016) 577.

[54] X. Wei, O. Izhvanov, C. Back, C.D. Haines, D.G. Martin, K.S. Vecchio, E.A. Olevsky, Spark plasma sintering of structure-tailored ultrahigh-temperature components: First step to complex net shaping, Journal of the American Ceramic Society 102(2) (2019) 548-558.

[55] M. Sakkaki, F.S. Moghanlou, M. Vajdi, M.S. Asl, M. Mohammadi, M. Shokouhimehr, Numerical simulation of heat transfer during spark plasma sintering of zirconium diboride, Ceramics International 46(4) (2020) 4998-5007.

[56] A. Pavia, L. Durand, F. Ajustron, V. Bley, G. Chevallier, A. Peigney, C. Estournès, Electro-thermal measurements and finite element method simulations of a spark plasma sintering device, Journal of Materials Processing Technology 213(8) (2013) 1327-1336.

[57] C. Wang, L. Cheng, Z. Zhao, FEM analysis of the temperature and stress distribution in spark plasma sintering: Modelling and experimental validation, Computational materials science 49(2) (2010) 351-362.

[58] S.M. Bagheri, M. Vajdi, F.S. Moghanlou, M. Sakkaki, M. Mohammadi, M. Shokouhimehr, M.S. Asl, Numerical modeling of heat transfer during spark plasma sintering of titanium carbide, Ceramics International 46(6) (2020) 7615-7624. [59] M. Fattahi, M.N. Ershadi, M. Vajdi, F.S. Moghanlou, A.S. Namini, M.S. Asl, On the simulation of spark plasma sintered TiB2 ultra high temperature ceramics: a numerical approach, Ceramics International 46(10) (2020) 14787-14795.

[60] F.S. Moghanlou, M. Vajdi, A. Motallebzadeh, J. Sha, M. Shokouhimehr, M.S. Asl, Numerical analyses of heat transfer and thermal stress in a ZrB2 gas turbine stator blade, Ceramics International 45(14) (2019) 17742-17750.

[61] S. Nekahi, K. Vaferi, M. Vajdi, F.S. Moghanlou, M.S. Asl, M. Shokouhimehr, A numerical approach to the heat transfer and thermal stress in a gas turbine stator blade made of $\mathrm{HfB}_{2}$, Ceramics International 45(18) (2019) 24060-24069.

[62] M. Vajdi, F. Sadegh Moghanlou, Z. Ahmadi, A. Motallebzadeh, M. Shahedi Asl, Thermal diffusivity and microstructure of spark plasma sintered TiB2SiCTi composite, Ceramics International 45(7, Part A) (2019) 8333-8344.

[63] F. Sadegh Moghanlou, M. Vajdi, J. Sha, A. Motallebzadeh, M. Shokouhimehr, M. Shahedi Asl, A numerical approach to the heat transfer in monolithic and $\mathrm{SiC}$ reinforced $\mathrm{HfB} 2, \mathrm{ZrB}_{2}$ and $\mathrm{TiB}_{2}$ ceramic cutting tools, Ceramics International 45(13) (2019) 15892-15897.

[64] R.F. Brito, S.R. Carvalho, S.M.M. Lima E Silva, Experimental investigation of thermal aspects in a cutting tool using comsol and inverse problem, Applied Thermal Engineering 86 (2015) 60-68.

[65] D.C. Ferreira, E.d.S. Magalhães, R.F. Brito, S.M.M. Lima E Silva, Numerical analysis of the influence of coatings on a cutting tool using COMSOL, The International Journal of Advanced Manufacturing Technology 97(1) (2018) 1305-1314 